University of Nebraska - Lincoln

DigitalCommons@University of Nebraska - Lincoln

2009

\title{
Two New Species of Compsolechia Meyrick (Lepidoptera: Gelechiidae) Associated with Casearia (Flacourtiaceae) in Coastal Dry-Forests of Western Mexico
}

\author{
David Adamski \\ Department of Entomology, National Museum of Natural History, Smithsonian Institution, P.O. Box 37012, \\ MRC 168, Washington, D.C., 20013- 7012, U.S.A., adamskid@si.edu \\ Karina Boege \\ Instituto de Ecologia, Universidad Nacional Autónoma de Mexico, Apartado Postal 70275, Ciudad \\ Universitaria, UNAM 04510, Mexico, D.F., kboege@servidor.unam.mx
}

Follow this and additional works at: https://digitalcommons.unl.edu/systentomologyusda

Part of the Entomology Commons

Adamski, David and Boege, Karina, "Two New Species of Compsolechia Meyrick (Lepidoptera: Gelechiidae) Associated with Casearia (Flacourtiaceae) in Coastal Dry-Forests of Western Mexico" (2009). USDA Systematic Entomology Laboratory. 52.

https://digitalcommons.unl.edu/systentomologyusda/52

This Article is brought to you for free and open access by the Entomology Collections, Miscellaneous at DigitalCommons@University of Nebraska - Lincoln. It has been accepted for inclusion in USDA Systematic Entomology Laboratory by an authorized administrator of DigitalCommons@University of Nebraska - Lincoln. 


\title{
TWO NEW SPECIES OF COMPSOLECHIA MEYRICK (LEPIDOPTERA: GELECHIIDAE) ASSOCIATED WITH CASEARIA (FLACOURTIACEAE) IN COASTAL DRY-FORESTS OF WESTERN MEXICO
}

\author{
David Adamski and Karina Boege
}

(DA) Department of Entomology, National Museum of Natural History, P.O. Box 37012, NHBE523, Smithsonian Institution, Washington, D.C. 20013-7012, U.S.A. (e-mail: David.Adamski@ars.usda.gov); (KB) Instituto de Ecología, Universidad Nacional Autónoma de Mexico, Apartado Postal 70275, Ciudad Universitaria, UNAM 04510, México, D.F. (e-mail: kboege@servidor.unam.mx)

Abstract. - Two new species of Compsolechia Meyrick (Lepidoptera: Gelechiidae), C. camilotus Adamski and C. vittatiella Adamski, are described from dry-forests in western Mexico. Larvae of both species were collected on leaves of Casearia nitida (L.) Jacq. (Flacourtiaceae), a new host record for the genus. Photographs of larvae and their shelters and adult moths are provided. In addition, illustrations of the male and female genitalia of the adults, larval chaetotaxal maps, and scanning electron micrographs for both species are included. The pupa of only C. camilotus was available for description.

Key Words: chaetotaxy, Chamela, genitalia, leafroller, leaftier, Neotropics, pupa, taxonomy

Compsolechia was proposed by Meyrick (1918), and he designated Anacampsis diortha Meyrick 1914 as its type species. Although the vast majority of the approximately 120 species assigned to the genus are Neotropical in distribution (Becker 1984), four species are known from Japan (Inoue 1954), one species is known from North America north of Mexico (Hodges 1983), and one species is recorded from Hawaii (Nakahara et al. 1992). No species of Compsolechia is known from Europe, the Indochinese Region, Africa, Australia, or New Zealand.

The larvae of Compsolechia appear to be leaf rollers. In the New World, Aiello (1977) has reared adults of Compsolechia perlatella (Walker) from larvae collected

* Accepted by David R. Smith within leaf-rolled shelters of Casearia guianensis (Aubl.) (Salicaceae) in Panama. Fatima et al. (1992) and Oliveira and Freitas (2004) report an undescribed species of Compsolechia that feeds on leaves of Qualea grandifolia Mart. (Vochysiaceae) in the Brazilian cerrado. In Japan, Compsolechia metagramma Meyrick is a leafroller on Spiraea japonica L. (Rosaceae) (PDF 2008), and in Hawaii, Compsolechia seductella Walker feeds on the flowers and fruits of Clidemia hirta (L.) D. Don. (Melastomataceae) (Nakahara et al. 1992).

The placement of species within Compsolechia and Anacampsis Curtis 1827 has been mostly arbitrary for nearly 100 years. Although both genera appear closely related, Meyrick (1918) proposed Compsolechia stating, "it [Compsolechia] 
is distinguished by the smooth palpi, cubital pecten, and hardly sinuate termen of the hindwings." Meyrick (1918) also stated that species of Anacampsis possess "slight but appreciable tufts of forewings...," a feature that Janse (1949) and Park (1988) observed to be absent in many species of the genus. Clearly, a comparative study of all morphologial features of the types of all species of Compsolechia, Anacampsis, and related genera is a first step in understanding their identities and the phylogenetic relationships within Anacampsinae. The above point is underscored by the complexity of morphological diversity within these taxa, figured in Clarke (1969).

The purpose of this study is to describe two new species of Compsolechia from the deciduous forests of western Mexico, to document their host associations with Casearia nitida, and to describe their immature stages and larval behavior.

\section{Materials And Methods}

Study sites are located at Eataćion de Biología Chamela (EBC), Universidad Nacional Autónoma de México, Jalisco, Mexico. The station is near the Pacific coast of Mexico $\left(19^{\circ} 30^{\prime} \mathrm{N}, 105^{\circ} 03^{\prime} \mathrm{W}\right)$, has an area of about 3,300 hectares, and is thought to have been undisturbed for hundreds of years because there is no evidence of either natural or anthropogenic fire (Maass and Martinez-Yrizar 2001). The vegetation in this region consists mainly of deciduous plant species intermixed with semi-deciduous species that are distributed primarily along several large streams within the forests (Lott 1987). Annual rainfall averages about $788 \mathrm{~mm}$ and is concentrated but not totally restricted to July through October (GarciaOliva et al. 2002). Mean temperature is about $25^{\circ} \mathrm{C}$, with less than a $5^{\circ} \mathrm{C}$ difference between the warmest and coolest months (Maass and Martinez-Yrizar 2001).

Larvae of Compsolechia camilotus Adamski, new species and $C$. vittatiella

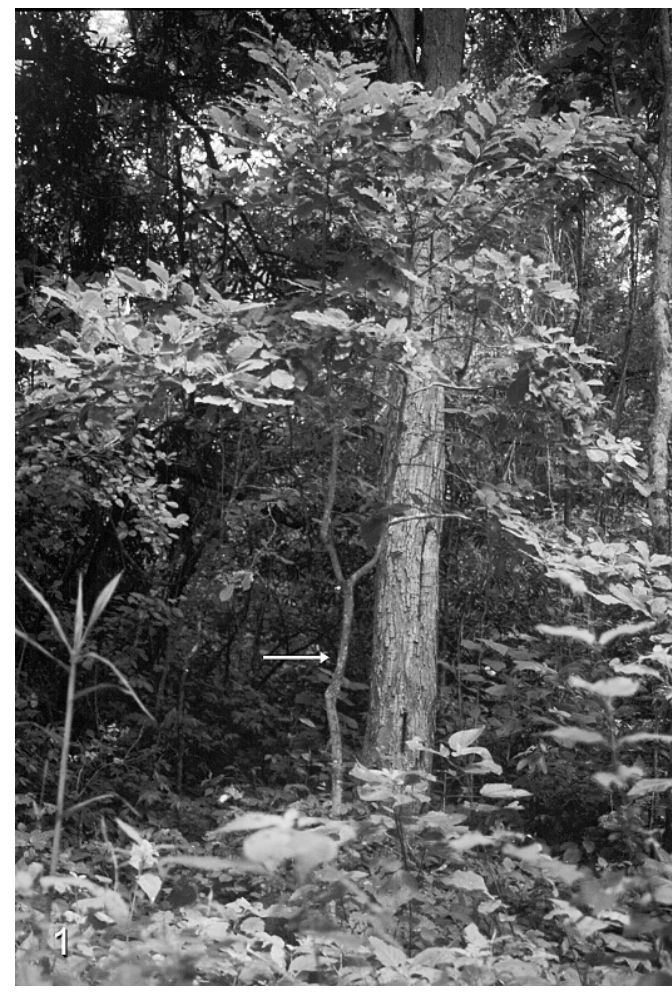

Fig. 1. Arrow pointing to a specimen of Casearia nitida in a dry-forest habitat in western Mexico.

Adamski, new species were found on leaves of the tropical deciduous tree Casearia nitida (L.) Jacq. (Flacourtiaceae) (Fig. 1). This species is distributed throughout the Neotropics from Mexico to South America. Casearia nitida grows from 2-6 meters in height in the forests that encompass EBC (Lott 1993). Leafflush and flowering occur during the first two weeks of the rainy season (between June and July), and seeds mature between August and September. Adults of $C$. camilotus were collected from a sheet illuminated by blacklight at or near the study sites where its larvae were collected.

For SEM study, larvae and pupae were cleaned in a full-strength solution of all-purpose cleaner (Formula $409^{\mathrm{TM}}$ detergent) and subsequently dehydrated in increasing concentrations of alcohol to absolute alcohol. After dehydration, specimens were critical point dried using 
a Tousimis critical point dryer, mounted on SEM stubs, and coated with goldpalladium $(40 / 60 \%)$ using a Cressington sputter coater. The ultrastructure of the larva and pupa was studied with an Amray 1810 scanning electron microscope at an accelerating voltage of $10 \mathrm{kV}$.

Gross morphological observations and measurements of the larva and pupa were made using a dissecting microscope (reflected light) with a calibrated micrometer. Genitalia were dissected as described by Clarke (1941) except mercurochrome and chlorazol black were used as stains. The Methuen Handbook of Colour (Kornerup and Wanscher 1978) was used as a color standard. Types and voucher specimens of immature stages from this study are deposited in the National Museum of Natural History, Smithsonian Institution, Washington, DC (USNM) and Instituto de Ecología, Universidad Nacional Autónoma de Mexico, Ciudad Universitaria, México, D.F. (UNAM). The senior author is the authority for the species described herein. Plant taxonomy, including nomenclature and authorship, follows GRIN (2008).

Results AND Discussion

\section{Compsolechia camilotus Adamski, new species}

(Figs. 2-23, 42-44)

Diagnosis.-Compsolechia camilotus is closest in forewing pattern to Compsolechia molybdina (Walsingham) from Guerrero, Mexico; its male genitalia differs from the latter by having a more elongate and hoodlike uncus, a larger and serpentine-shaped gnathos, a deeply dissected valva, two digitate lobes of the juxta, widely divergent arms of the vinculum, and a shorter aedeagus. The female of $C$. molybdina is unknown. Although differing in forewing pattern, Compsolechia cassidata (Meyrick) from British Guiana has male genitalia most similar to those of C. camilotus. Both species share an elongate, hoodlike uncus, a large serpentine-shaped gnathos, a deeply dissected valva, digitate lobes of the juxta, and a short aedeagus. However, C. camilotus differs from the latter species by having a more elliptical distal region of the upper part of the valva, shorter digitate lobes of the lower part of the valva, and shorter lobes of the juxta.

Description.-Head: Vertex and frontoclypeus gray with yellow scales along margins; ocellus present; scape and flagellomeres of antenna yellow; outer and inner surfaces of labial palpus yellow or yellow intermixed with brown scales on segment 2, gradually darkening to brown on segment 3 . Proboscis pale yellow.

Thorax: Scales of tegula and mesonotum aguoti, pale gray on basal $2 / 3$, with narrow gray band and narrow pale-gray band on distal 1/3. Foreleg with coxa, femur and tibia pale yellow; tarsomeres countershaded with gray dorsally and pale yellow ventrally, each with narrow band of yellow scales along apical margin; midleg and hind leg with coxa and femur pale yellow, tibia and tarsomeres patterned as foreleg. Forewing (Fig. 2) length 8.0-9.6 mm ( $=11)$; scales pale gray, tipped with gray, intermixed with few gray and dark-gray scales; base with small dark-gray patch along costa; costa gray extending posteriorly, forming suffuse, subtriangular marking near midcell and suffuse subapical marking, overlapping wide, palegray subapical band, extending inwardly, forming outwardly rounded, archshaped pattern beyond middle, extending linearly to tornus; subtornal area with large suffused gray patch; subovate gray or dark-gray submarginal mark near middle; fringe gray. Undersurface pale gray. Hind wing gray.

Abdomen: Male Genitalia (Figs. 3-4) with uncus elongate, slightly shorter than tegumen, hoodlike, setose; gnathos cylindrical, serpentine-shaped, with narrow basal curve and broad distal curve, 

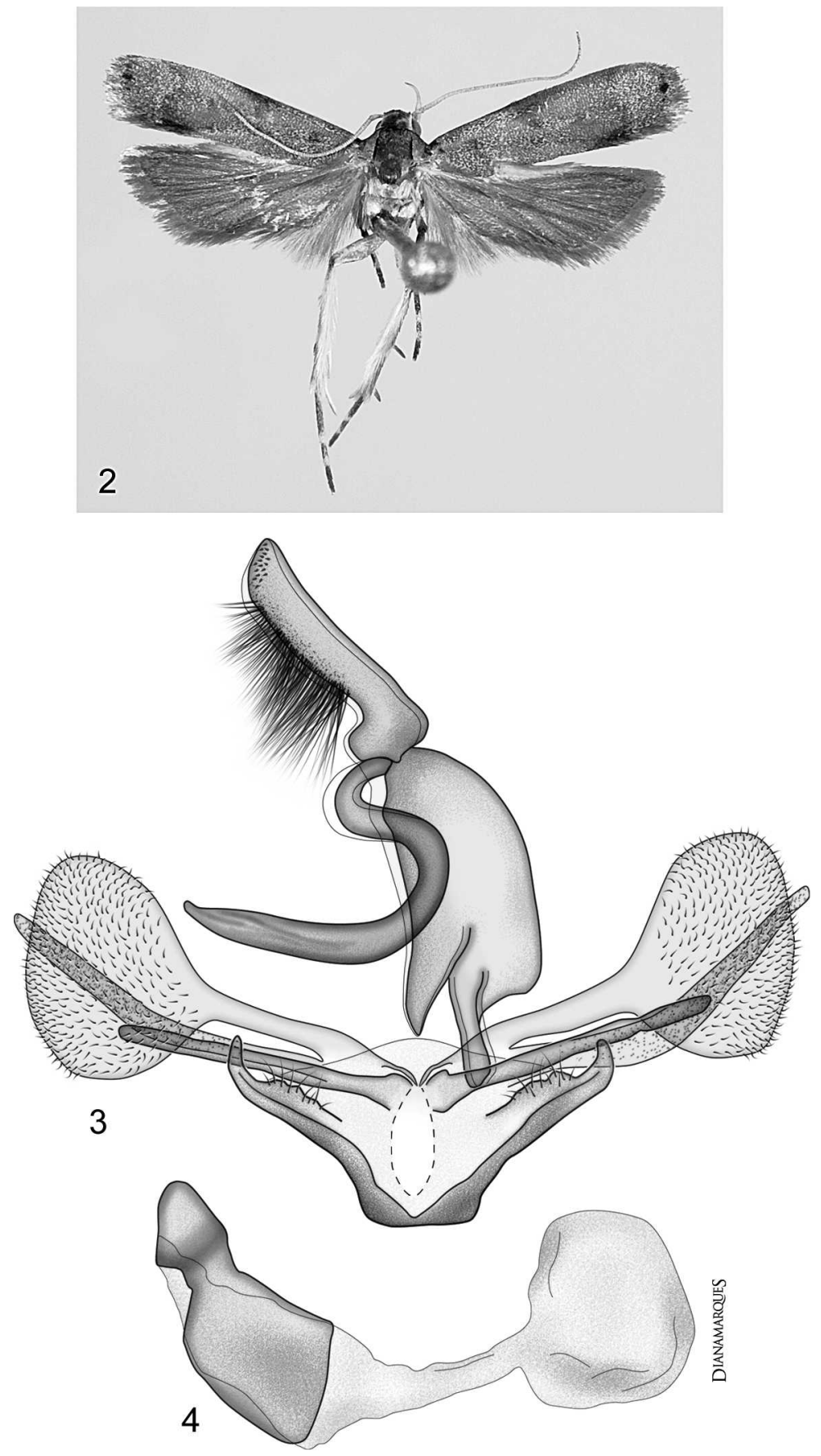

Figs. 2-4. Compsolechia camilotus. Fig. 2. Holotype. Figs. 3-4. Male genitalia. 3, Genital capsule. 4, Aedeagus.

extending well beyond posterior con- rounded apically and upturned; anterior tours of tegumen, apex acuminate; arms margin of arm irregularly crenulate and of vinculum widely divergent from ob- sparsely setose; valva deeply dissected, tuse base; distal part of arms narrowly forming two parts; upper part spatulate, 


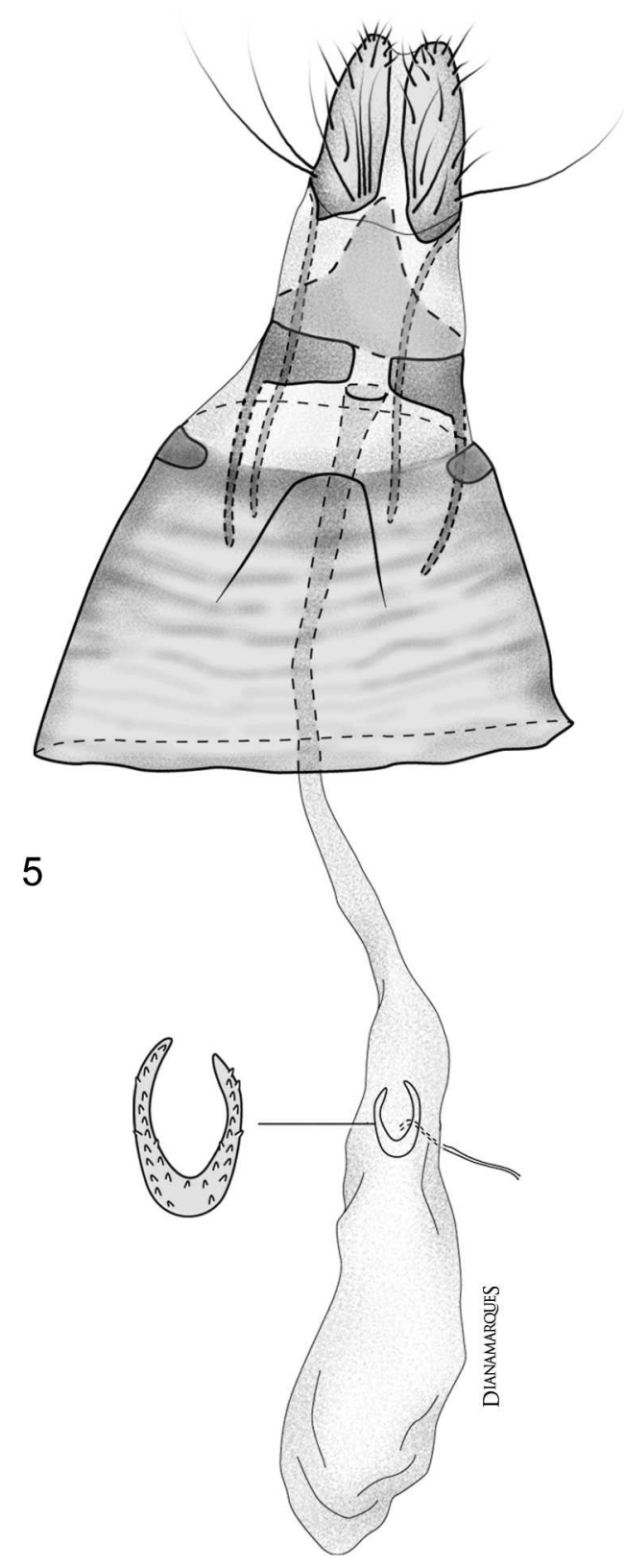

Fig. 5. Female genitalia of Compsolechia camilotus.

finely setose; lower part digitate, setose, extending slightly beyond upper part; juxta absent or represented by pair of digitate, sparsely setose lobes; aedeagus cylindrical base, narrowed apically, abruptly dilated subapically, forming broadly rounded, conical bulb; ductus ejaculatoris extending anteriorly, abruptly dilated posteriorly, forming large spherical sac. Female Genitalia (Fig. 5) with ovipositor short; papillae anales elliptical with dense cluster of short setae on apical end intermixed with long setae sparsely spaced throughout; apophyses posteriores slightly less than twice length of apophyses anteriores; eighth tergum triangular, extending and curved ventrolaterally on anterior end, forming two opposable arms posterolateral to ostium; ductus bursae elongate, gradually widening, forming elongate corpus bursae; posterior end of corpus bursae with sparsely spinulate, opened-ended ringlike sclerite proximad to inception of ductus seminalis; seventh sternum subtriangular; seventh tergum wide, extending and curved ventrolaterally, forming two short, opposable arms on posterior end.

Types.-Holotype ô : "México: Jalisco: Estación de Biologia Chamela, Universidad Nacional Autónomia de México, r.f. Casearia nitida, leaf-roller, C-5, $\mathrm{RN}=35$, 7 July 2002, Col[lector] K. Boege," “ ‘ Genitalia Slide by D. Adamski, USNM 83359" [green label]. Deposited in USNM.

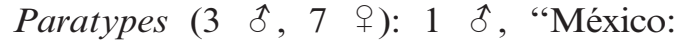
Jalisco: Estación de Biologia Chamela, Universidad Nacional Autónomia de México, r.f. Casearia nitida, leaf-roller, C45, RN = 48, 7 July 2002, Col[lector] K. Boege," " o Genitalia Slide by D. Adamski, USNM 83363" [green label]; 1 §, same label data as above except, "C-5, RN = 37, 7 July 2005," “ ๙ , Genitalia Slide by D. Adamski, USNM 83364" [green label]; $1 \hat{\delta}$, same as above except, "Group $2, \mathrm{RN}=24,7$ July 2004" [specimen not dissected]; 1 9 , same as above except, "C-5, RN = 32, 7 July 2003”, “o, Genitalia Slide by D. Adamski, USNM 83365" [green label]; 1 ㅇ, same as above except, "C-5, RN = 34, 7 July 2002," " $q$ Genitalia Slide by D. Adamski, USNM 83366" [green label]; 1 옹, same as above except, "Group $2, \mathrm{RN}=23,2$ July 2004" [specimen not dissected]; 1 , same as above except, 

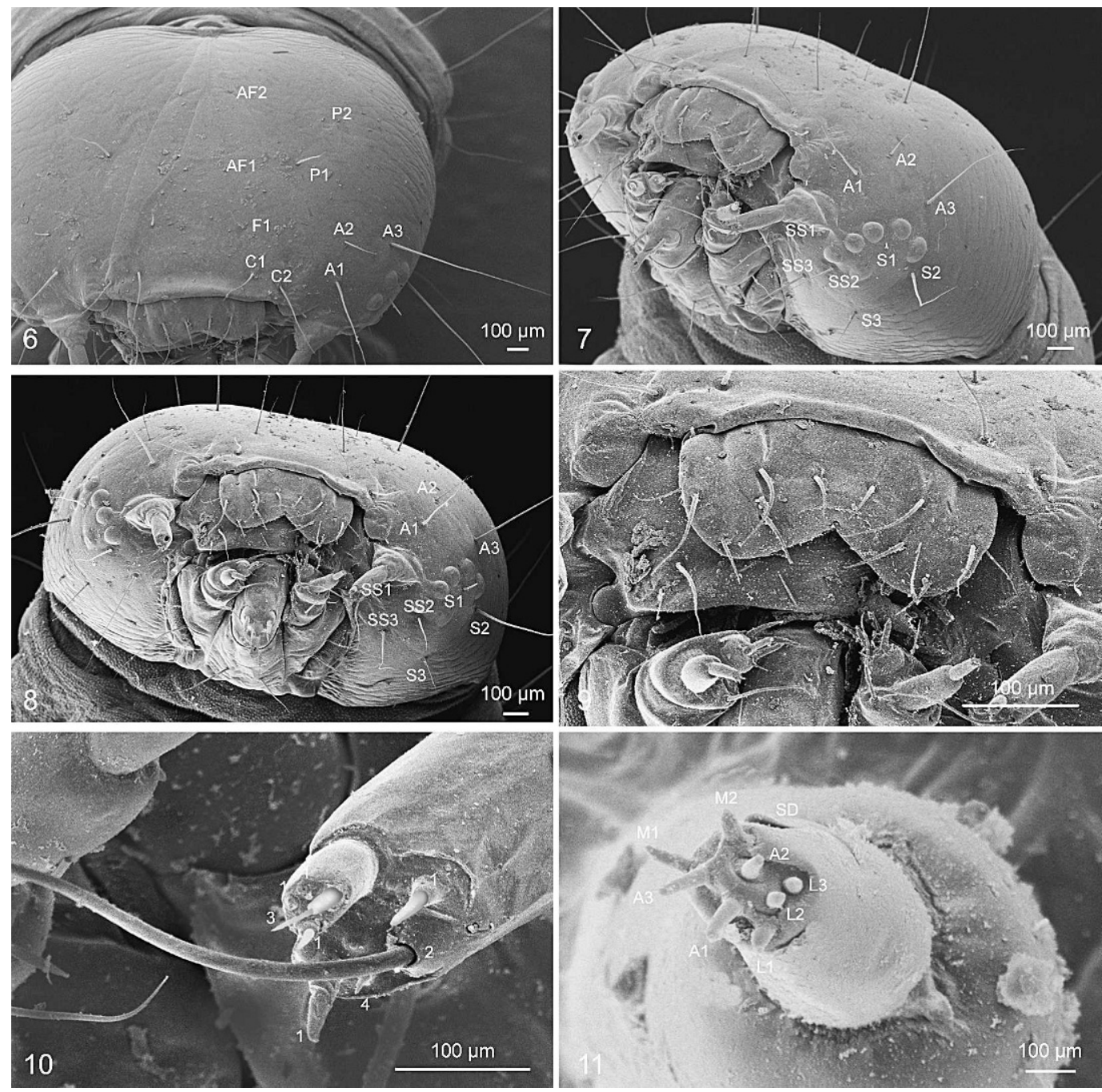

Figs. 6-11. Scanning electron micrographs of larva of Compsolechia camilotus. 6, Head, frontal view. 7, Head, lateroventral view. 8, Head, ventral view. 9, Oral area, frontal view. 10, Apical sensilla of antenna, frontolateral view. $1=$ sensilla basiconica, $2=$ sensilla chaetica, $3=$ sensillum styloconicum, $4=$ sensillum trichodeum. 11, Apical sensilla of left maxillary palpus, frontolateral view. A2 = sensillum styloconicum; A1, A3, M1, M2, L1, L2, L3 = sensilla basiconica; SD = sensillum digitiform.

"Group 2, RN = 22, 2 July 2004," [specimen not dissected]; 1 +, same as above except, "C-5, RN = 33, 7 July 2001" [specimen not dissected]; $2+$, same as above except, " $19^{\circ} 31^{\prime} \mathrm{N}, 105^{\circ} 03^{\prime} \mathrm{W}, 4-11$ July 2006, Col[lector] D. Adamski, blacklight" [specimens not dissected]. Six paratypes in USNM. 4 in UNAM.

Other Specimens Examined.-Compsolechia molybdina (Walsingham): Paratype $\delta$ : “Amula, 6,000 f[ee]t., Guerrero,
MEXICO, VIII, 18, (H.H. Smith), G[o]dm[an] S[a]lv[i]n, 65731"; "3389”; "Anacampsis molybdina W[a]ls[ingha]m, PARATYPE"; " के Genitalia Slide by D. Adamski, USNM 83339" [green label], USNM; Compsolechia cassidata (Meyrick): Holotype $\delta$ : British Guiana, Mallali, 3-13, ô BM Slide No. 5880. Examined from photograph in Clarke (1969).

Etymology.-The specific epithet, $c a-$ milotus, honors Camilo Gimenez-Boege, 

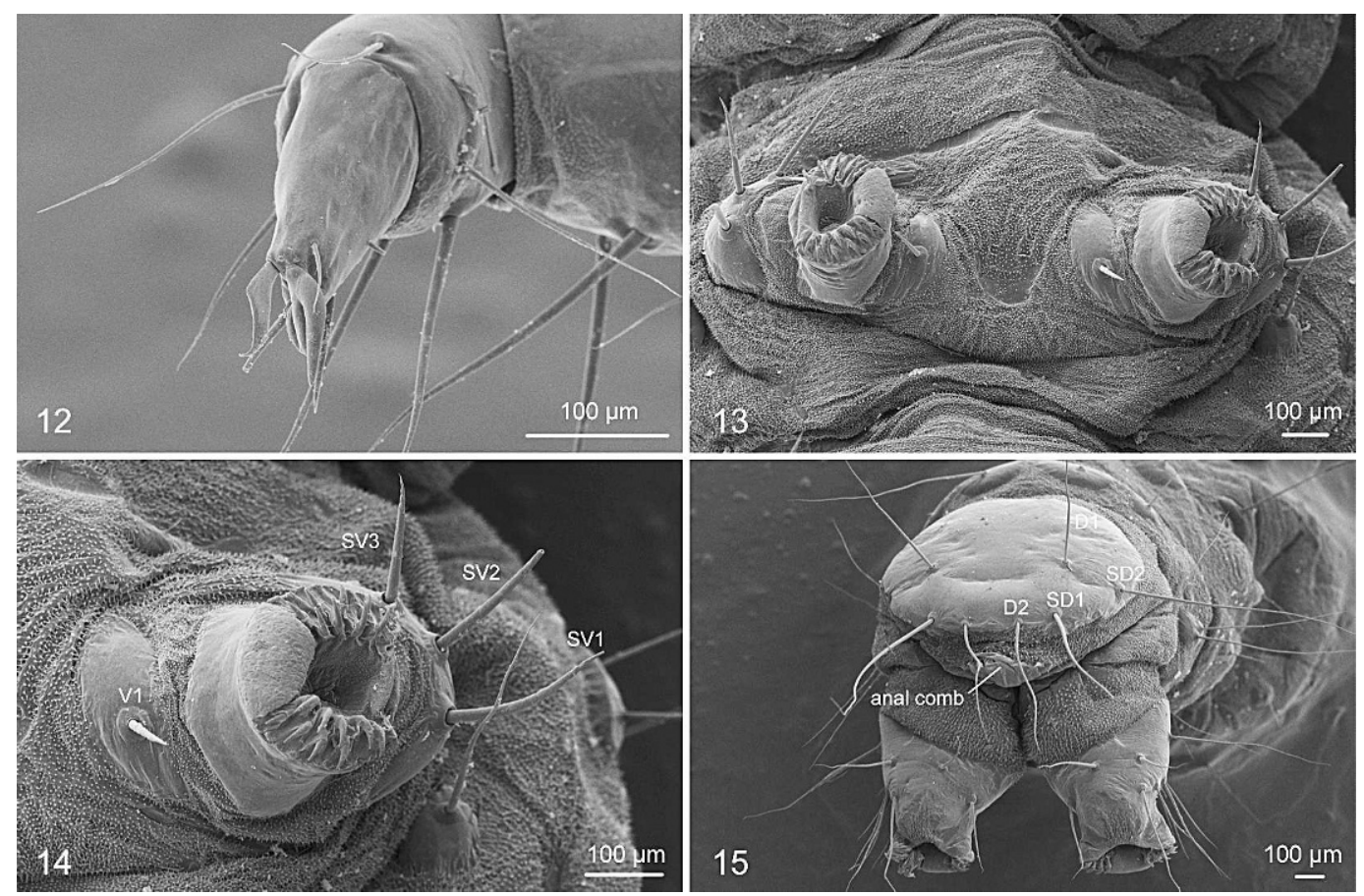

Figs. 12-15. Scanning electron micrographs of Compsolechia camilotus. 12, Right tarsal claw on T1, inner view. 13, Prolegs on A5, apical view, 14, Left proleg on A5, apical view. 15, Anal plate on A10, caudal view.

whose parents, Karina and Jacquine, took care of my logistical needs while I was their guest in Mexico.

Larva (Figs. 6-21, 42-44).- - Length 12.7-18.2 mm ( $\mathrm{n}=3)$. Body yellowish green to green; pinacula pale brown, slightly darker than body; head capsule, prothoracic shield, thoracic legs, anal plate and anal comb on A10 yellowish brown; spiracle on $\mathrm{T} 1$ and A8 slightly larger than spiracles on A1-A7.

Head (Figs. 6-11, 16): Hypognathous, epicranial suture long, epicranial notch deep, forming two large dorsal hemispheres; adfrontal sclerites meeting near end of epicranial suture; AF2 at level of apex of frons about twice the length of AF1 and same length of F1; AF1 closer to $\mathrm{F} 1$ than to AF2; P1 slightly dorsolateral to $\mathrm{AF} 1$, about $3 \times$ longer than $\mathrm{P} 2$; $\mathrm{P} 2$ dorsolateral to $\mathrm{P} 1$ and in line with $\mathrm{A} 1$; L1 lateral to and in line with $\mathrm{P} 1 ; \mathrm{C} 1-\mathrm{C} 2$ diagonally orientated on ventrolateral margin of frons, of equal length; A3 above stemma 1, about same length as A1, both setae at least $3 \times$ longer than A2; A2 in straight line with A1; stemmata in crescent-shaped pattern, with stemmata 1-5 forming broad arc, stemma 6 ventrolateral to stemma 4; S3 ventroposterior to $\mathrm{S} 2$; $\mathrm{S} 2$ beneath stemma 1 , at least $3 \times$ lengths of $\mathrm{S} 3$ and $\mathrm{S} 1 ; \mathrm{S} 1$ between stemmata 2 and 3; SS2 adjacent to stemma 5; SS3 beneath antenna, slightly closer to SS2 than to SS1; SS1 slightly posterolateral to condyle of mandible; mandible with 2 subequal setae adjacent to condyle, with 3 large dentitions of subequal lengths on upper part of distal ridge and 3 smaller dentitions of nearly equal lengths on lower part of distal ridge (Fig. 21); spinneret porrect.

Thorax (Figs. 12, 16): T1 with Lgroup setae on pinaculum anteroventral to spiracle; L1 about twice length of L2, with L3 slightly shorter than L2; L1 

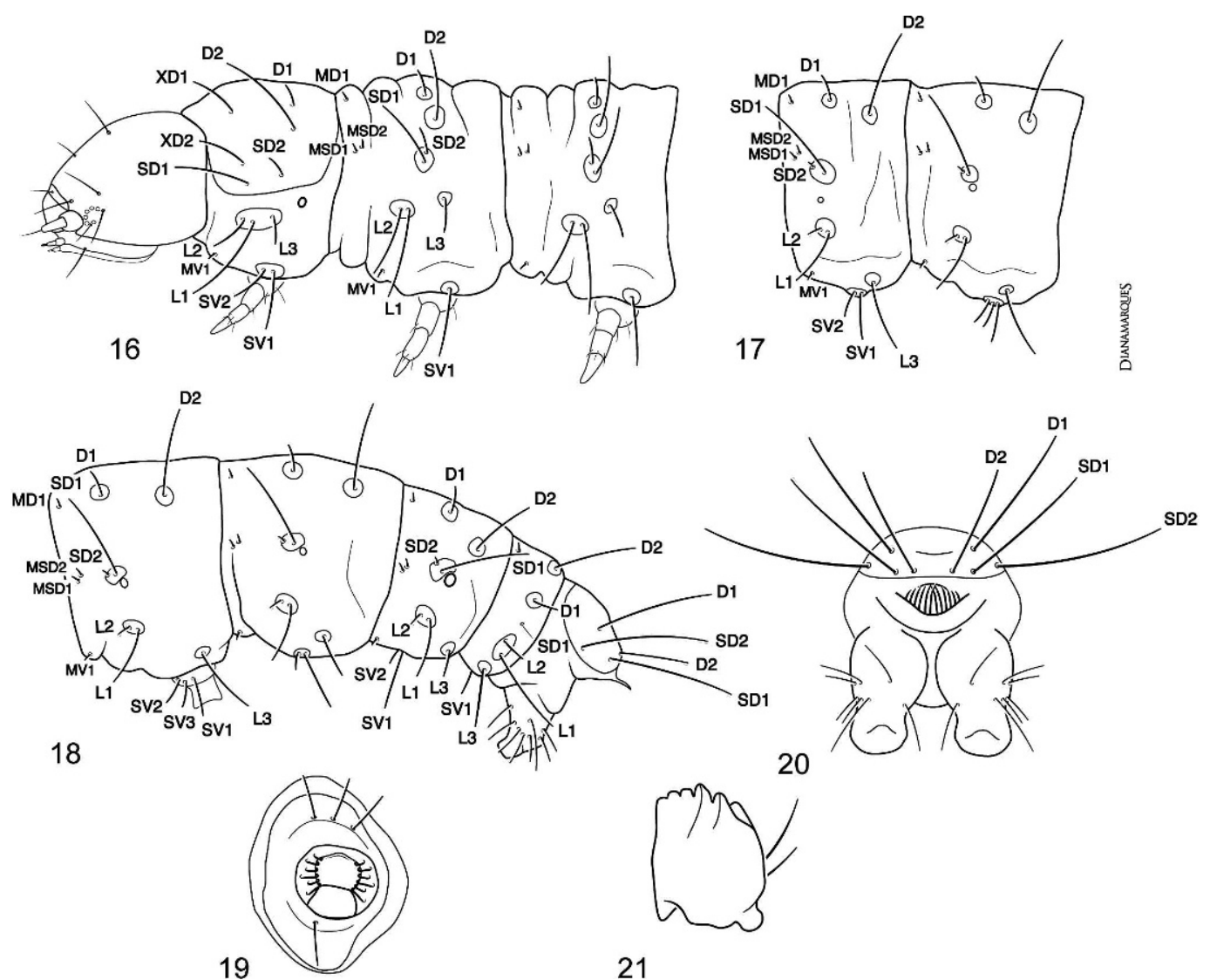

Figs. 16-21. Chaetotaxal maps and mandible of Compsolechia camilotus. 16, Head and thorax, lateral view. 17, A1-A2, lateral view. 18, A6-A10, lateral view. 19, Proleg, apical view. 20, A10, anal plate, caudal view. 21, Left mandible, inner surface.

about twice the distance from L3 than from L2; L2 and L3 in near straight line, with L1 slightly ventral; shield with SD1 slightly longer than and in straight line with XD2 and XD1; SD1 about $3 \times$ distance from XD1 than from XD2; SD2 equidistant from SD1 and XD2, about as long as, and anterior to, D1; D2 slightly longer than SD1, equidistant from XD2 and XD1; D1 and XD1 in straight line parallel with longitudinal axis; SV1 slightly longer than SV2; MV1 anteroventral to L-group pinaculum near margin of segment; V1's approximate, posterior to caudal margin of coxae (not shown). Thoracic legs ending with claw juxtaposed by broad, flattened, sickleshaped seta on lateral surface of apical end (Fig. 12). T2-T3 (Fig. 16): D2 about $3 \times$ length of D1, both on separate pinacula; MD1 between D1-D2 pinacula; SD1 about $3 \times$ length of SD2, on same pinaculum anterior to D-group setae; MSD1-MSD2 slightly above SDgroup pinaculum near anterior margin of segment; L1 slightly longer than L2, both on same pinaculum, anterior to SDgroup setae; L3 about 1/2 length of L1L2, slightly posterior to D2 and in vertical with or slightly anterior or posterior to SV1; MV1 ventroanterior to L1-L2 pinaculum near anterior margin of segment; V1's about $3 \times$ distance apart as V1's on T1, setae about midway between cephalic and caudal margins of coxae (not shown). 


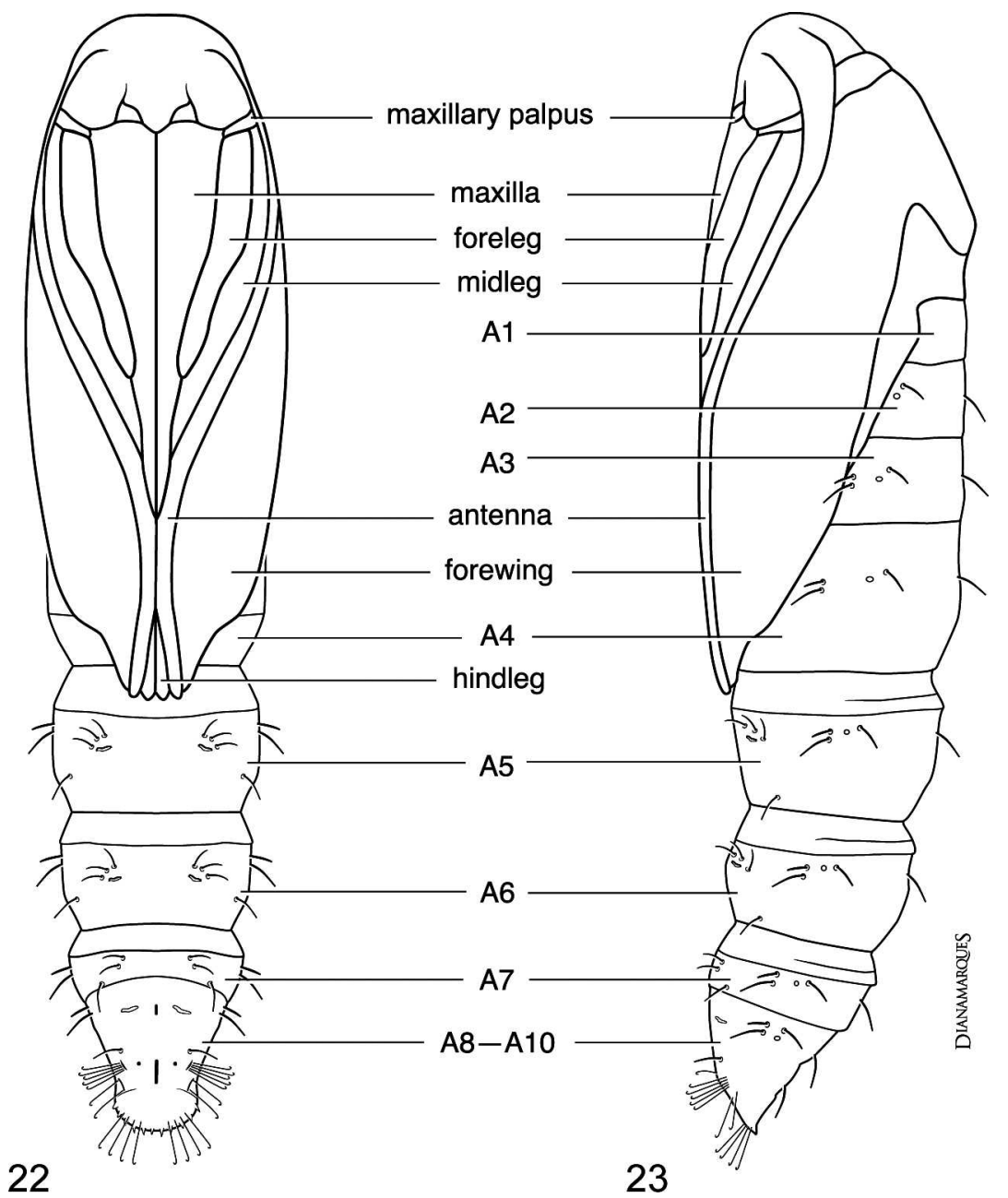

Figs. 22-23. Pupa of Compsolechia camilotus. 21, Ventral view. 22, Lateral view.

Abdomen (Fig. 17): A1-A2 with D2 about 3-4× length and slightly ventral to D1; MD1 near anterior margin of segment, in straight line or slightly below D1 pinaculum; SD1 above spiracle (with space between setal socket, spiracle about diameter of pinaculum) on A1; SD1 dorsoanterior to spiracle on A2-A8, with pinaculum bearing SD1 and SD2 abutting spiracle (Figs. 17-18); SD2 minute, on anterior margin of pinaculum (SD2 observable only with high magnification); MSD1-MSD2 slightly above SD-group pinaculum near anterior margin of segment; L1 about $2.5 \times$ as long as L2, on same pinaculum; L3 in vertical line or slightly anterior or posterior to D2; MV1 anteroventral to L1-L2 pinaculum near anterior margin of segment; $\mathrm{SV}$-group bisetose on A1, trisetose on A2; A3-A6 (Figs. 13-14, 18-19) with four pairs of protuberant prolegs, crochets biordinal along cephalic and caudal margins, abruptly absent laterally, forming membranous gap; mesial margin of planta with wide, rounded plate, forming space between cephalic and caudal crochet rows; setae as above except MD1 always below D1 pinaculum, MSD1MSD2 adjacent, in straight line with $\mathrm{SD}$-group pinaculum, and SV-group in linear pattern; A7 as above except SV- 
group bisetose; A8 as above except pinaculum bearing SD1 more anteriorly confluent with spiracle; A9 with all setae in vertical line. Anal plate on A10 (Figs. 15, 18, 20) with SD1 slightly longer than SD2 and D1; SD1 about $4 \times$ distance from SD2 than from D2; D2 about half length of SD1; anal fork with 12-14 elongate, flattened, apically pointed processes, gradually shortened laterally from middle; median two pairs of processes of anal fork convergent, other processes straight; prolegs with biordinal crochets flanking wide medial gap.

Pupa (Figs. 22-23)._-Length $9.6 \mathrm{~mm}$ $(\mathrm{n}=1)$, yellowish brown, smooth, finely setose; sclerites of antennae widely separated anteriorly, gradually convergent from beyond midlength of sclerites of foreleg, fused short distance beyond sclerites of maxillae, gradually divergent posteriorly, exposing distal part of sclerites of hind legs; paired nodular scars of prolegs on A5-A6; A6-A10 fused, movable as a unit; A8-A10 with apically hooked setae on lateral and ventral surfaces (Figs. 22-23).

Host.-Casearia nitida (L.) Jacq. (Flacourtiaceae).

Biology.-Caterpillars of C. camilotus were found in early July at the beginning of the rainy season within shelters that were rolled from part of a leaf cut away by the larva along one side of the midvein from the apex to about midlength (Figs. 42-44). Compsolechia camilotus appears to be univoltine.

\section{Compsolechia vittatiella Adamski, new species}

(Figs. 24-41, 45-47)

Diagnosis.-The relationship of $C$. vittatiella to other Compsolechia is difficult to determine because of several unusual features, particularly in the male genitalia. These features include an elongate uncus, confluent with tegumen, not broadened or hoodlike, a ventrally elongate vinculum with lateral arms that are confluent with the valva, and short and broad valvae.

Description.-Head: Scales of frontoclypeus gray tipped with pale gray, gradually darkening to vertex; frontoclypeus and vertex with pale-yellow scales along margins; ocellus present; scape of antenna pale yellow, each flagellomere pale orange intermixed with pale yellow along distal margin; outer and inner surfaces of labial palpus with basal segment dark brown; segment 2 pale yellow, with narrow, brown basal band; segment 3 with basal $2 / 3$ pale yellow, intermixed with dark-brown scales distally, gradually to dark brown on distal $1 / 3$. Basal part of proboscis pale yellow, dark brown distally.

Thorax: Tegula and mesonotum gray. Foreleg and midleg brown intermixed with pale-gray scales along distal margin of tibia and tarsomeres; hind leg pale gray with brown spurs, brown tarsomeres intermixed with pale-gray scales along distal margins. Forewing (Fig. 24) length $7.1-7.2 \mathrm{~mm}(\mathrm{n}=3)$; gray intermixed with dark-gray and brown scales; large dark brown subtriangular marking beyond base; marking demarcated by narrow yellow boarder; irregular, narrow, palegray subapical line extending inwardly, forming rounded arch beyond middle, extending linearly to tornus; submarginal spots dark brown, some spots demarcated with few yellow scales; fringe gray. Undersurface brownish gray. Hind wing pale brown basally, gradually darkening to apex.

Abdomen: Male Genitalia (Figs. 2526) with tegumen elongate, confluent with uncus; uncus setose, with two small, slightly downcurved conical setae near apex; gnathos confluent with contours of tegumen; vinculum elongate, dorsally divergent, forming 2 short arms, confluent with valva, demarcated dorsally by irregular rows of divergent setae originating near smooth middle area; valva 


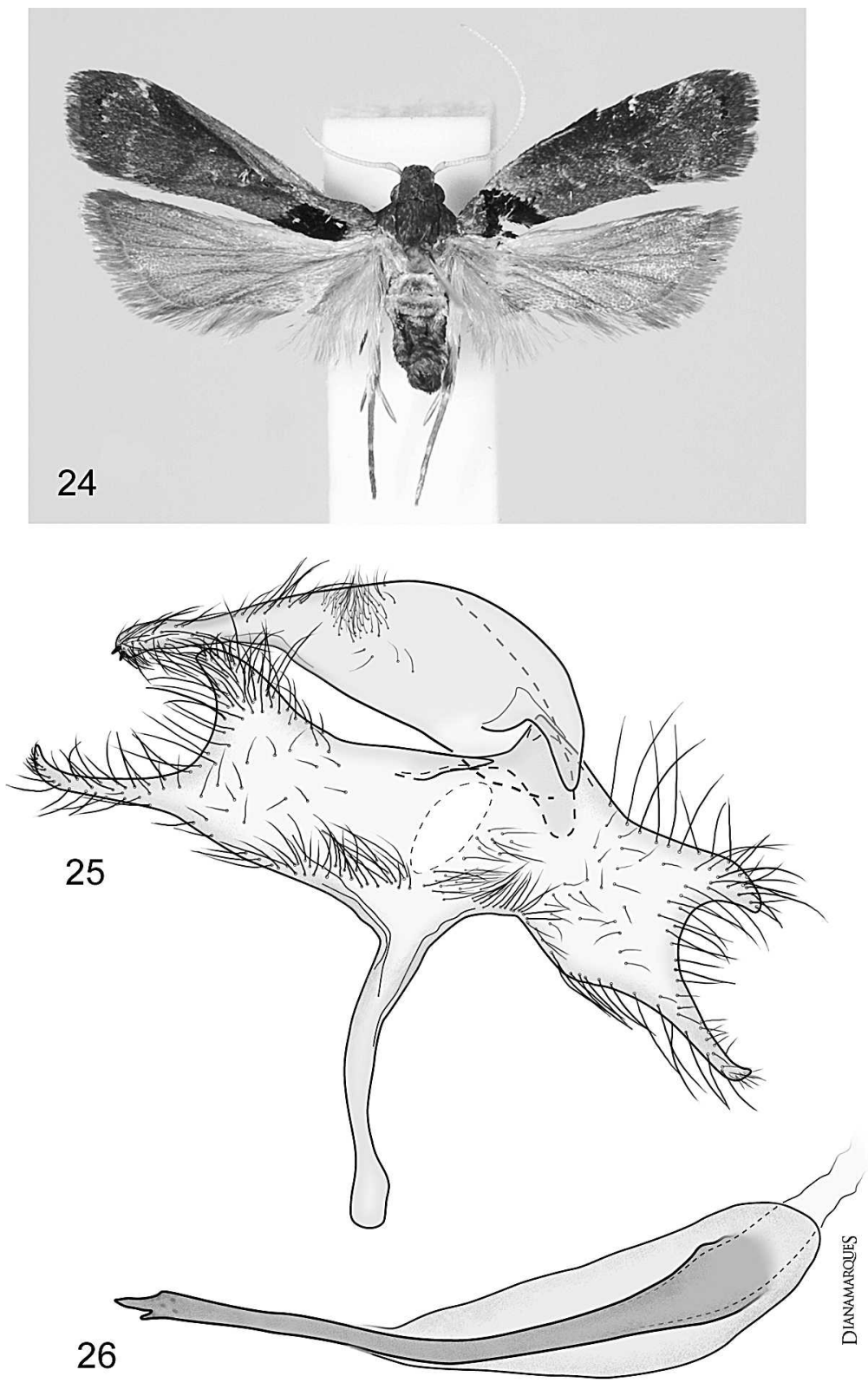

Figs. 24-26. Compsolechia vittatiella. Fig. 24. Holotype. Figs. 25-26. Male genitalia. 25, Genital capsule. 26, Aedeagus.

setose marginally, wide, broadly dissected distally, forming short, slightly downcurved costal lobe and long ventral digitus; dorsal articulation of valva digitate; aedeagus elongate, broadly curved, basal $2 / 3$ widened, gradually narrowed distally; an inner sclerotized tube extending beyond bulbous part to sparsely spinulate apex. Female Genitalia: Unknown.

Types.-Holotype ô: "México: Jalisco: Estación de Biologia Chamela, Universidad Nacional Autónomia de México, r.f. Casearia nitida, leaf-tier, RN = 31, 3 July 2004, Col[lector] K. Boege," “\& Genitalia Slide by D. Adamski, USNM 83360" 

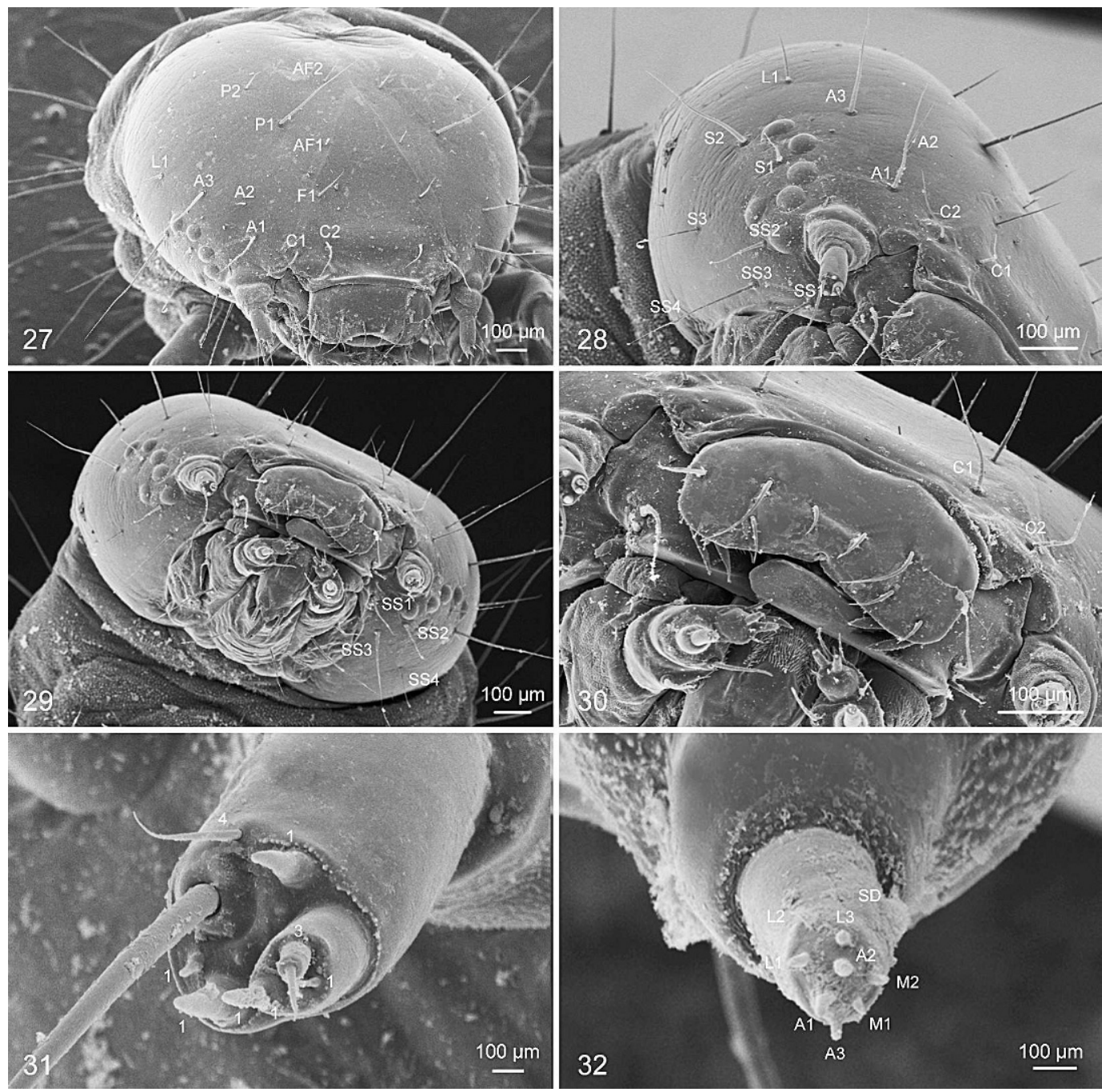

Figs. 27-32. Scanning electron micrographs of larva of Compsolechia vittatiella. 27, Head, frontal view. 28, Head, ventrolateral view. 29, Head, ventral view. 30, Oral area, frontal view. 31, Apical sensilla of right antenna. $1=$ sensilla basiconica, $2=$ sensilla chaetica, $3=$ sensillum styloconicum, $4=$ sensillum trichodeum. 32, Apical sensilla of right maxillary palpus. A2 = sensillum styloconicum; A1, A3, M1, M2, L1, L2, L3 = sensilla basiconica; $\mathrm{SD}=$ sensillum digitiform.

[green label]. Deposited in USNM. Paratypes $\left(\begin{array}{llll}2 & \delta\end{array}\right): 1$ §, "México: Jalisco: Estación de Biologia Chamela, Universidad Nacional Autónomia de México, r.f. Casearia nitida, leaf-tier, C-16, $\mathrm{RN}=46,7$ July 2002, Col[lector] K. Boege," “ \$ Genitalia Slide by D. Adamski, USNM 83361" [green label]; 1 $\delta$, same label data as above except, "RN = 32, 3 July 2004," " of Genitalia Slide by D. Adamski, 5846" [yellow label]. One paratype in USNM, one in UNAM.

Remarks.-The generic placement of C. vittatiella is tentative. Although its assignment to a new genus may become necessary in the future, this action should be based on evidence from a comprehensive phylogenetic analysis of Compsolechia and related genera within Anacampsinae. 

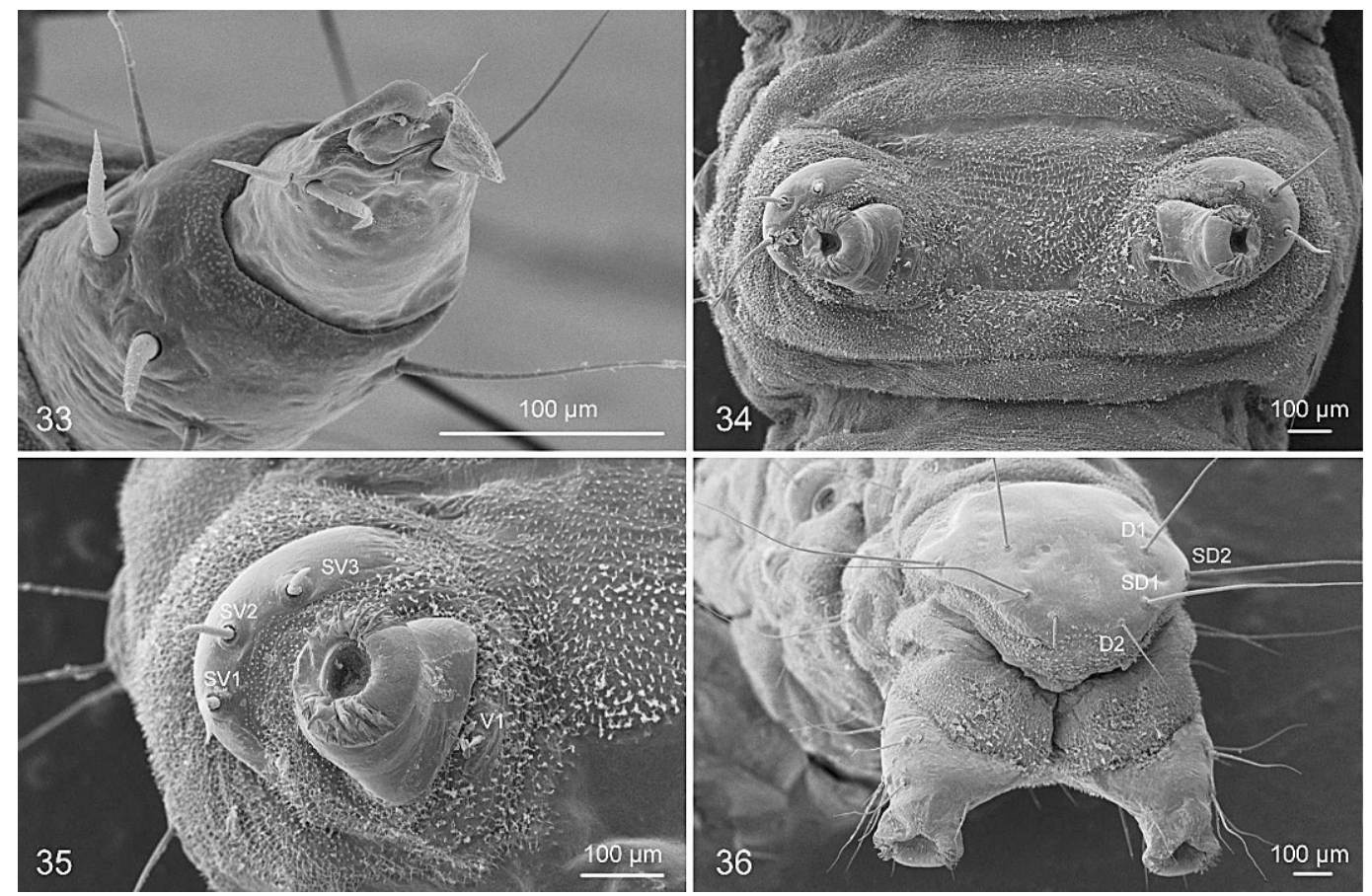

Figs. 33-36. Scanning electron micrographs of larva of Compsolechia vittatiella. 33, Left tarsal claw on T2, inner view. 34, Prolegs of A5, apical view. 35, Right proleg on A5, apical view. 36, Anal plate on A10, caudal view.

Etymology.-The specific epithet, vittatiella, is derived from the Latin vittatus meaning striped and refers to the color pattern of the larva.

Larva (Figs. 27-41, 45-47).-_Length 9.6-10.1 mm $(\mathrm{n}=2)$. Body pale greenish yellow with transverse, dark-red bands; bands on T3-A1 merged, forming one wide band; head capsule, prothoracic shield, thoracic legs, and anal plate yellowish brown; spiracles on $\mathrm{T} 1, \mathrm{~A} 1$, and $\mathrm{A} 8$ about equal in size, at least twice diameter of spiracles on A2-A7.

Head (Figs. 27-32, 41): Hypognathous, epicranial suture long, epicranial notch deep, forming two large dorsal hemispheres; adfrontal sclerites meeting near end of epicranial suture; AF2 at level of apex of frons, about twice length of AF1 and equal in length to $\mathrm{F} 1$; AF1 closer to $\mathrm{F} 1$ than to AF2; P1 slightly dorsolateral to AF1, about $3 \times$ longer than P2; P2 dorsolateral to $\mathrm{P} 1$ and in line with $\mathrm{A} 1$;
L1 lateral to and in line with P1; C1-C2 diagonally orientated on ventrolateral margin of frontoclypeus, of equal length; A3 above stemma 1, about same length as or slightly longer than A1, each at least $3 \times$ longer than A2; A2 in straight line with A1; stemmata in an arc, with stemmata 15 forming broad arc, stemma 6 ventrolateral to stemma 4; S3 ventroposterior to S2; A3 above stemma 1, about same length as $\mathrm{A} 1$, each at least $3 \times$ longer than $\mathrm{A} 2$; $\mathrm{A} 2$ in straight line with A1; S3 ventroposterior to S2; SS4 posterolateral to SS2; SS2 adjacent to stemma 5; SS3 beneath antenna, slightly closer to SS2 than to SS1; SS1 slightly posterolateral to condyle of mandible; mandible with 2 subequal setae adjacent to condyle, with 2 large dentitions on upper part of distal ridge and 2 dentitions of subequal lengths on lower part of distal ridge (Fig. 41); spinneret porrect.

Thorax (Figs. 33, 37-38): T1 with Lgroup setae on pinaculum anterior to 

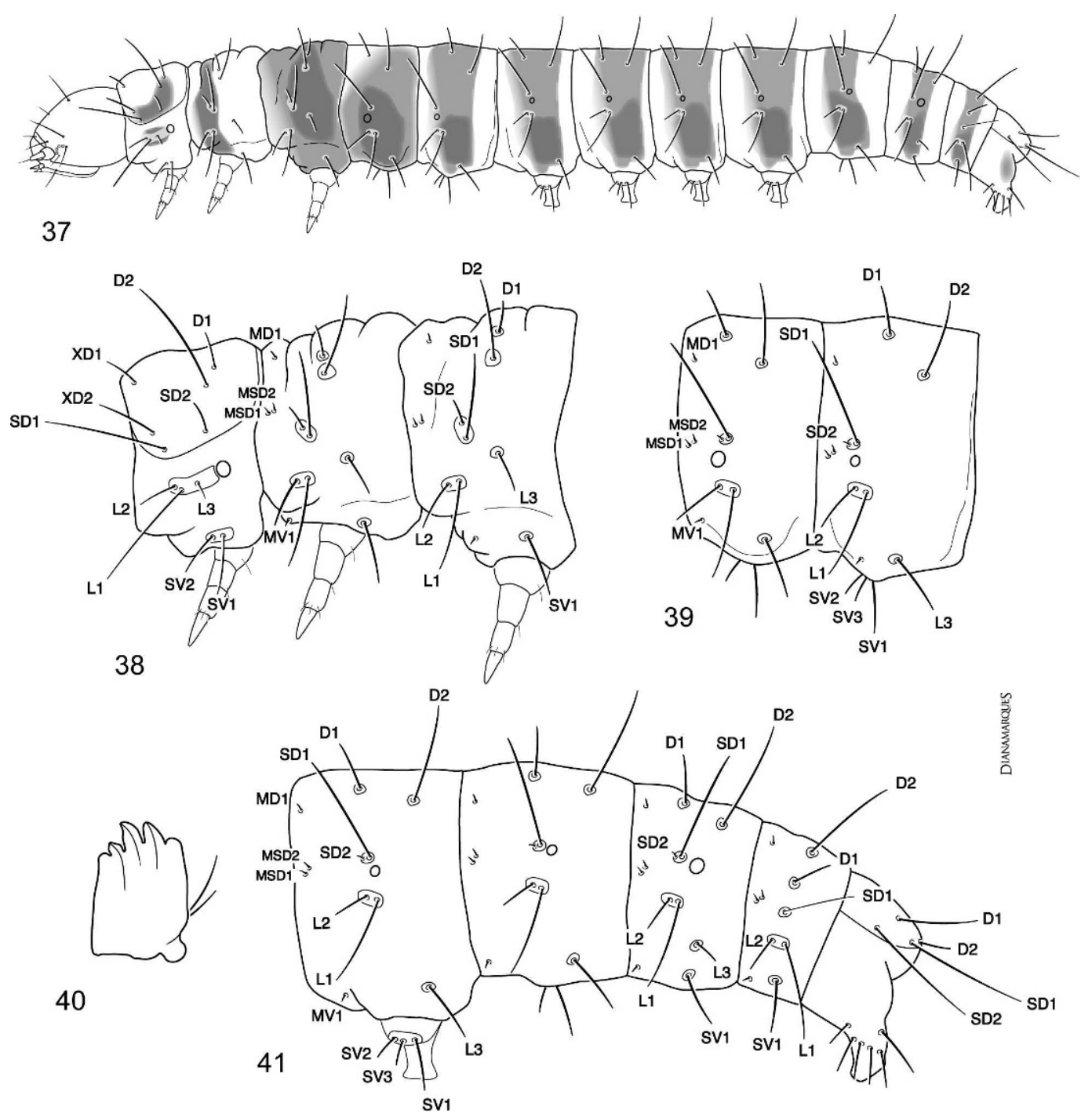

Figs. 37-41. Chaetotaxal maps and mandible of larva of Compsolechia vittatiella. 37, Larva showing setal pattern and color pattern, lateral view. 38, T1-T3, lateral view. 39, A1-A2, lateral view. 40, Left mandible, inner surface. 41, A6-A10, lateral view.

and abutting spiracle; L1 and L2 approximate, near anterior margin of pinaculum; L1 posteroventral to L2, L3 near middle of pinaculum; L1 about $3 \times$ length of L2, L3 slightly shorter than L2; shield with SD1 about 1/3 longer than XD2 and XD1, setae along anterior margin in straight line; SD1 at least $6 \times$ distance from XD1 than from XD2; SD2 as long as D1, equidistant to SD1 and $\mathrm{XD} 2$, anterior to D2-D1; D2 as long as
SD1, equidistant to XD2 and XD1; D1 posterior to D2 and SD2, in straight line, parallel to body axis; SV1 slightly longer than SV2; V1's approximate, posterior to caudal margin of coxae (not shown). T2T3 (Figs. 33, 37-38): D2 about 2.5× length of D1, each seta on separate pinaculum; D2 pinaculum larger than D1 pinaculum; MD1 near anterior margin of segment, in straight line or slightly below D1 pinaculum; SD1 about $3 \times$ 

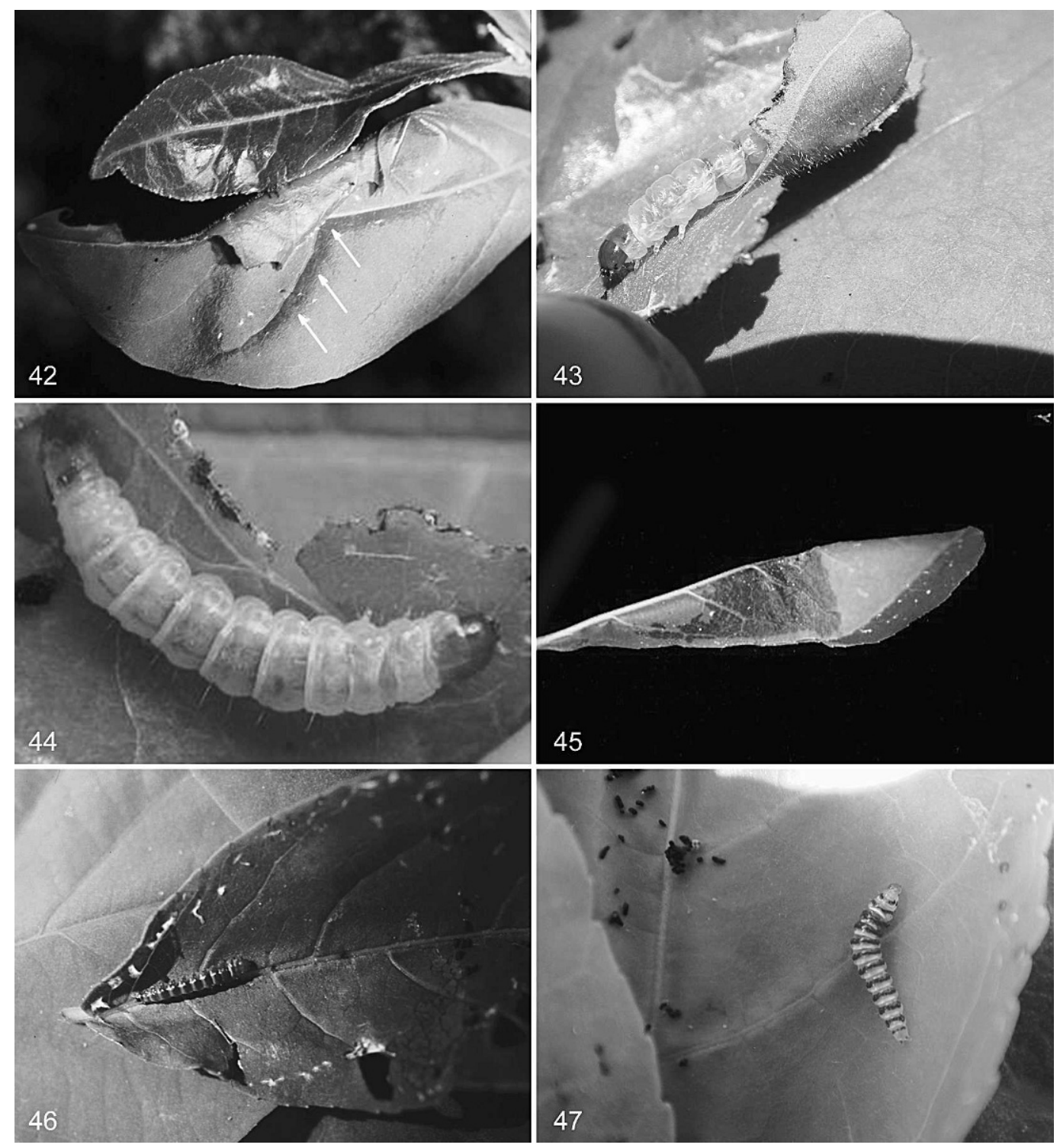

Figs. 42-47. Larvae and larval shelters of Compsolechia camilotus and C. vittatiella. 42-44, Compsolechia camilotus. 42, Shelter made from leaf-rolling larva. 43, Exposed larva from shelter. 44, Larva. 45-47, Compsolechia vittatiella. 45, Shelter made from leaf-tying larva. 46, Exposed larva from shelter. 47, Larva.

longer than SD2, both on same pinaculum anterior to D1; MSD1-MSD2 near anterior margin of segment, slightly above Lgroup pinaculum; L1 about twice as long as L2, both on same pinaculum, slightly anterior to SD-group pinaculum; L3 slightly shorter or equal in length to L2, slightly anterior to SV1; MV1 near anterior margin of segment, ventroanteri- or to L1-L2 pinaculum; V1's about $4 \times$ as far apart as V1's on T1, setae about midway between cephalic and caudal margins of coxae (not shown). Legs ending with single claw juxtaposed by broad, flattened, sickle-shaped seta on lateral surface of apical end (Fig. 33).

Abdomen (Figs. 37-39): A1-A2 with D2 about 1/3 longer than and ventral to 
D1; MD1 near anterior margin of segment, below D1 pinaculum; SD1 about as long as D2, slightly dorsoposterior to spiracle on A1, dorsoanterior to spiracle on A2-A8; SD2 minute, near anterior margin of pinaculum with SD1; MSD1MSD2 in straight line with or slightly below SD-group pinaculum; L1 slightly longer than L2, on shared pinaculum, slightly posterior to spiracle on A1-A2, slightly anterior to spiracle on A3-A8; L3 in vertical line with, posterior, or anterior to D2; SV1 bisetose on A1, trisetose on A2 (on same pinaculum, in triangular pattern); MV1 near anterior margin of segment, ventroanterior to L1-L2 pinaculum; V1's as above; A3-A6 (Figs. 34-35, 37 , 40) with 4 pairs of protuberant prolegs, crochets biordinal along cephalic and caudal margins, absent laterally, forming gap; mesial margin of planta with wide, rounded plate, forming space between cephalic and caudal crochet rows (Figs. 34-35); A7 as above except SVgroup bisetose; A8 as above except pinaculum bearing SD1-SD2 and pinaculum bearing L1-L2 slightly more anterior of spiracle than on A1-A7, and D2, L3, $\mathrm{SV} 1$, and V1 approximating vertical line (V1 not shown); A9 with setae approximating vertical line, and L3 absent (V1 not shown); anal plate on A10 (Figs. 36$37,40)$ with SD1 and SD2 about equal in lengths; SD1 about $3 \times$ distance from SD2 than from D2; D1 slightly shorter than SD1-SD2, posterior to SD2; anal comb absent; prolegs with biordinal crochets flanking wide medial gap.

Host._Casearia nitida (L.) Jacq. (Flacourtiaceae).

Biology.-Caterpillars of C. vittatiella were found at the beginning of the rainy season (July) within shelters constructed from a single leaf that is folded from the midvein, exposing the undersurface of the leaf, and held together tightly from the leaf margins with silk (Figs. 45-47). Compsolechia vittatiella appears to be univoltine.
Parasitoid.-Xiphosomella sp. (Ichneumonidae).

\section{Acknowledgments}

We thank Kevin Tuck, Microlepidoptera Section, The Natural History Museum, London, United Kingdom, for help with examination of type specimens of Compsolechia and Anacampsis; Scott Whittaker, Manager, Scanning Electron Microscopy Laboratory, Smithsonian Institution, Washington, DC, USA, for his suggestions on fixation of larvae and scheduling of SEM time; Robert Kula, Systematic Entomology Laboratory, ARS, USDA, Washington, DC, for identifications of the parasitic Hymenoptera; and Diana Marques, scientific illustrator, Lisboa, Portugal, for the illustrations of the male and female genitalia, chaetotaxal maps of the larva and pupa, and the preparation of all the plates.

\section{Literature Cited}

Aiello, A. 1977. Smithsonian Tropical Research Institute (STRI). //striweb.si.edu/aiello/details. php?id=455. Accessed 25 March 2008.

Becker, V. 1984. Gelechiidae, pp. 44-53. In Heppner, J. B., ed. Atlas of Neotropical Lepidoptera, Checklist: Part I, Micropterigidae - Immoidea. Dr. W. Junk, The Hague, The Netherlands, xxvii +112 pp.

Clarke, J. F. G. 1941. The preparation of slides of the genitalia of Lepidoptera. Bulletin of the Brooklyn Entomological Society 36: 149-161.

. 1955-70. Catalogue of the Type-Specimens of Microlepidoptera in the British Museum (Natural History) described by Edward Meyrick. 8 Vols. [Vol. 6. 1969, 537 pp.]. British Museum (Natural History), London.

Fatima, M., C. B. Costa, A. T. Oliveira-Filho, and P. S. Oliveira. 1992. The role of extrafloral nectaries in Qualea grandiflora (Vochysiaceae) in limiting herbivory: an experiment of ant protection in cerrado vegetation. Ecological Entomology 17: 363-365.

Garcia-Oliva, F., A. Camou, and J. M. Maass. 2002. El clima de la región central de la costa del pacífico mexicano, pp. 3-10. In Nogúera Aldrete, A. N., J. H. Vega Rivera, A. N. García Aldrete, and M. Quesada Avenda"no, eds. Historia natural de Chamela. Instituto de Biología, UNAM, Mexico City. 
GRIN. 2008. USDA, ARS, National Genetic Resources Program. Germplasm Resources Information Netwoek - (GRIN) [Online Database]. National Germplasm Resources Laboratory, Beltsville, Maryland, URL: http:// www.ars-grin.gov/cgi-bin.npgs/html/index.pl. Accessed 29 March 2008.

Hodges, R. W. 1983. Gelechiidae, pp. 19-25. In Hodges, R. W. ed. Check List of the Lepidoptera of America North of Mexico. E. W. Classey Ltd. and The Wedge Entomological Research Foundation, xxiv + 284 pp.

Inoue, H. 1954. Check List of the Lepidoptera of Japan. Part 1: Micropterigidae - Phaloniidae, Rikusuisha, Tokyo, Japan, xiii + 429 pp.

Janse, A. J. T. 1949. Gelechiidae, pp. 255-256. In The Moths of South Africa, Transvaal Museum, Pretoria 5(1): 255-256.

Kornerup, A. and J. H. Wanscher. 1978. Methuen Handbook of Colour. 2nd ed. Methuen and Co., Ltd., London, 243 pp.

Lott, E. J. 1987. Floristic diversity and structure of upland and arroyo forests of coastal Jalisco. Biotropica 19: 228-232.

1993. Annotated checklist of the vascular flora of the Chamela bay region. Jalisco Mexico. Occasional Papers of the California Academy of Science 148: 1-60.
Maass, M. and A. Martinez-Yrizar. 2001. NPP Tropical Forest: Chamela, Mexico, 1982-1995. Data set. Available on-line [http://www.daac. ornl.gov] from Oak Ridge National Laboratory Distributed Active Archive Center, Oak Ridge, Tennessee, U.S.A.

Meyrick, E. 1914. Descriptions of new South American Micro-Lepidoptera. Transactions of the Entomological Society of London 1914: 229-284.

1918. Exotic Microlepidoptera. Vol. 2. Taylor \& Francis, London, Reprinted by E.W. Classey, Ltd., 1969. 640 pp.

Nakahara, L. M., R. M. Burkhart, and G. Y. Funasaki. 1992. Review and status of biological control of Clidemia in Hawaii, pp. 452-465. In Stone, C. P., C. W. Smith, and J. T. Tunison, eds. Alien Plant Invasions in Native Ecosystems in Hawaii. University of Hawaii Press, 904 pp.

Oliveira, P. S. and A. V. L. Freitas. 2004. Ant-plantherbivore interactions in the neotropical cerrado savanna. Naturwissenschaften 91: 557-570.

Park, K. T. 1988. Systematic study on the genus Anacampsis (Lep., Gelechiidae) in Japan and Korea. TINEA 12(16): 135-155.

PDF. 2008. www.invasive.org/needed/pdfs/asianv2/ Spiraeajaponica.pdf. Accessed 27 March 2008. 